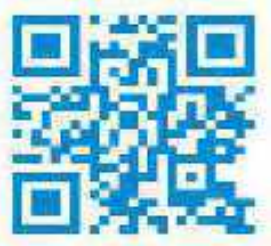

Scan to know paper details and author's profile

\title{
Comparative Assessment of Three Toothpastes and Prophylactic Polishing Paste as A Method of Iron Stain Removal in Primary Teeth: An in-Vitro Study
}

\author{
Dr. Devendra Patil, Dr. Komal Nanavati, Dr. Monica Yadav, Dr. Shantanu Deshpande,
}

Dr. Aishwarya Kamble \& Dr. Farhin Katge

\begin{abstract}
Aim: To compare and assess the efficacy of three toothpastes compared to prophylactic polishing paste as iron stain removal method in extracted primary teeth.

Method: Sixty extracted primary anterior teeth were decoronated at cementoenamel junction, followed by filling the pulp chamber with flowable composite. The teeth were then immersed in ferrous sulphate solution and digital images were obtained. The teeth were subjected to electric tooth brushing using Colgate ${ }^{\circledR}$ Visible White (Group A), Himalaya ${ }^{\circledR}$ Sparkling White (Group B) and Biomed ${ }^{\circledR}$ Superwhite (Group C) toothpastes. Prophylactic polishing paste (Group D) was used as control for stain removal. Post-intervention digital images were obtained and color parameter differences $\left(\mathrm{L}^{*}\right.$, $\mathrm{a}^{*}, \mathrm{~b} *$, hue, chroma and $\Delta \mathrm{E}$ ) were evaluated using image color summarizer software. The data was then statistically analysed using one way ANOVA test. Intergroup analysis was done using bon ferroni multiple comparison test.

Results: Significant differences in $\mathrm{L}^{*}$ and $\mathrm{b}^{*}$ colour parameters were obtained for Group A, B and D (p < 0.05); however, $\mathrm{a}^{*}$ parameter did not show a significant change in values for any group. A significant difference was observed in terms of chroma in groups A, C and D. No significant difference was observed in hue parameter values for all four groups. Intergroup comparison of $\Delta \mathrm{E}$ revealed significant differences between groups D ( $\mathrm{p}<0.05)$ and group A, B and C respectively.
\end{abstract}

Keywords: extrinsic dental stain, iron, primary teeth, dentifrices.

Classification: NLMC Code: WU 101.5

Language: English

London

LJP Copyright ID: 392872 Journals Press 



\title{
Comparative Assessment of Three Toothpastes and Prophylactic Polishing Paste as A Method of Iron Stain Removal in Primary Teeth: An in-Vitro Study
}

\author{
Dr. Devendra Patil ${ }^{\alpha}$, Dr. Komal Nanavati ${ }^{\sigma}$, Dr. Monica Yadav ${ }^{\rho}$, Dr. Shantanu Deshpande ${ }^{\oplus}$, \\ Dr. Aishwarya Kamble ${ }^{*}$ \& Dr. Farhin Katge ${ }^{\S}$
}

\section{ABSTRACT}

Aim: To compare and assess the efficacy of three toothpastes compared to prophylactic polishing paste as iron stain removal method in extracted primary teeth.

Method: Sixty extracted primary anterior teeth were decoronated at cementoenamel junction, followed by filling the pulp chamber with flowable composite. The teeth were then immersed in ferrous sulphate solution and digital images were obtained. The teeth were subjected to electric tooth brushing using Colgate ${ }^{\circledR}$ Visible White (Group A), Himalaya ${ }^{\circledR}$ Sparkling White (Group B) and Biomed ${ }^{\circledR}$ Superwhite (Group C) toothpastes. Prophylactic polishing paste (Group D) was used as control for stain removal. Post-intervention digital images were obtained and color parameter differences ( $L^{*}, a^{*}, b^{*}$, hue, chroma and $\Delta E$ ) were evaluated using image color summarizer software. The data was then statistically analysed using one way ANOVA test. Intergroup analysis was done using bon ferroni multiple comparison test.

Results: Significant differences in $L^{*}$ and $b^{*}$ colour parameters were obtained for Group $A, B$ and $D(p<0.05)$; however, $a^{*}$ parameter did not show a significant change in values for any group. A significant difference was observed in terms of chroma in groups $A, C$ and $D$. No significant difference was observed in hue parameter values for all four groups. Intergroup comparison of $\Delta E$ revealed significant differences between groups $D(p<0.05)$ and group $A, B$ and $C$ respectively.
Conclusion: A regular dental prophylaxis remains the best method for iron stain removal in children. Although newer dentifrices for stain removal are available they are not as efficient as dental prophylaxis.

Keywords: extrinsic dental stain, iron, primary teeth, dentifrices.

Author $\alpha$ : MDS lecturer,Department of Pediatric and Preventive Dentistry,Terna Dental College, Sector 22, Plot 12, Phase II, Nerul (west), Navi Mumbai- 400706

$\sigma:$ Postgraduate student,Department of Pediatric and Preventive Dentistry,Terna Dental College, Sector 22, Plot 12, Phase II, Nerul (west), Navi Mumbai- 400706

р: MDS Professor and Head of Department, Department of Oral Pathology and Microbiology, Terna Dental College, Sector 22, Plot 12, Phase II, Nerul (west), Navi Mumbai- 400706

Q. MDS lecturer, Department of Pediatric and Preventive Dentistry, Terna Dental College, Sector 22, Plot 12, Phase II, Nerul (west), Navi Mumbai- 400706 $¥$ : Postgraduate student, Department of Pediatric and Preventive Dentistry, Terna Dental College, Sector 22, Plot 12, Phase II, Nerul (west), Navi Mumbai- 400706 §: MDS Professor and Head of Department, Department of Pediatric and Preventive Dentistry, Terna Dental College, Sector 22, Plot 12, Phase II, Nerul (west), Navi Mumbai- 400706.

\section{INTRODUCTION}

Esthetic dentistry is an essential component in modern dental practice. Dental esthetics exerts a key role in a person's self-image, confidence and personality. ${ }^{1}$ In a study by Gupta et al. (2019) it was concluded that children are affected 
psychologically by negative social judgements due to problems in dental appearance. ${ }^{2} \mathrm{~A}$ similar study by Abanto et al (2011) stated that development of abstract thinking and concept of self-image occurs around the age of 6 years. At this time, any disorder related to esthetics may psychologically distress the child due to the judgement of their peers. $^{3}$

One of the various dilemmas in esthetic dentistry is discoloured teeth. Tooth discoloration is broadly divided into two types, discoloration due to intrinsic factors when the inner layer of enamel or dentin becomes discoloured. It is usually due to systemic or congenital causes like blood disorders, ingestion of certain drugs disorders like enamel hyploplasia etc. ${ }^{4}$ The other cause is discoloration due to extrinsic factors. Extrinsic discoloration occurs due to the build-up or retention of external stains within the salivary pellicle covering the tooth surfaces by chemical alterations. This build up may be due presence of chromogens in foods and drinks e.g. coffee, tea etc, smoking habit or certain medications. ${ }^{5}$

Iron formulations are routinely prescribed for children younger than 2 years of age to improve iron uptake as well as to help prevent iron deficiency and iron- deficiency anemia. ${ }^{4}$ Studies done by Nordbo H et al. (1982) $)^{6}$, Watts A et al. $(2001)^{7}$ and Christofides A et al. (2006) ${ }^{8}$ have documented black staining on the teeth of children taking iron supplements in form of syrups, drops or some other preparation. These stains can be easily removed in a dental setup using a low- speed handpiece with a rotary brush and prophylactic polishing paste.

Nowadays, a wide range of dentifrices, which specifically concentrate on the problem of tooth discoloration are available. Most of these products are incorporated with abrasive systems and additional chemical agents that supplement abrasive action. These agents prevent stain buildup by using a physical mode of action to remove stains during tooth brushing. ${ }^{9}$ Few such readily available dentifrices are Colgate ${ }^{\circledR}$ Visible White, Himalaya ${ }^{\circledR}$ Sparkling White and Biomed $^{\circledR}$
Superwhite toothpaste which have been used in this study. Colgate ${ }^{\circledR}$ Visible White contains silica and pyrophosphate which help in prevention of surface staining due to plaque formation. Himalaya ${ }^{\circledR}$ Sparkling White toothpaste contains papaya and pineapple extracts. These extracts render papain and bromelain which help in whitening of teeth. Biomed ${ }^{\circledR}$ Superwhite toothpaste contains bromelain, a pineapple extract that aids in stain reduction. These newly introduced whitening toothpastes could be used at home for the removal of iron stains.

Hence, the aim of this in vitro study was to compare and assess the efficacy of three toothpastes (Colgate $^{\circledR}$ Visible White, Biomed ${ }^{\circledR}$ Superwhite, and Himalaya ${ }^{\circledR}$ Sparkling White) compared to prophylactic polishing paste as iron stain removal method in extracted primary teeth.

\section{MATERIALS AND METHODS}

\subsection{Sample size}

Sample size was determined in concordance to results from a previous study ${ }^{4}$ through $G^{*}$ power software (version 3.0.10 with alpha at 0.05 and beta at less than 0.2 (power > 80\%). The total sample size calculated was 60 (15 per group).

\subsection{Ethical approval}

Approval of the study was obtained from the Institutional review Board Ethics Committee (IRB-EC), protocol approval number isTDC/EC/ 14/2020.

\subsection{Preparation of samples}

Sixty primary anterior teeth extracted due to physiologic mobility or orthodontic reasons were included in the current study. Any teeth with caries, restorations, developmental defects, enamel cracks, or external discoloration were excluded. The teeth were cleaned manually to remove the soft tissue residue from the surface following which they were stored in sterile $0.9 \%$ saline at room temperature till further use. 
All the teeth were immersed in 5.25\% sodium hypochlorite solution (Chloraxid 5.25\%, PPH Cerkamed Wojciech Pawlowski, Poland) for 30 minutes. After rinsing the teeth were cut at the cementoenamel junction (CEJ) and the pulp chamber was cleared of all the remnants using a high speed handpiece and round bur. The prepared pulp chamber was air dried followed by etchingwith 36\% phosphoric acid (Blue Etch 36\% phosphoric acid, PPH Cerkamed Wojciech Pawlowski, Poland) for 30 seconds. Bonding agent (3M Single bond universal adhesive, Neuss, Germany) was applied after rinsing and drying the pulp chamber,and light cured for 20 seconds. Flowable composite (Beautifil Flow, Shofu INC. Kyoto, Japan) was injected in the pulp chamber and light cured using Ivoclar Vivadent Bluephase N M Light Cure Unit (New York, USA) for 20 seconds. The teeth were then placed in ferrous sulfate solution (Tonoferon drops, East India pharma works Ltd., India) for 30 hours for the purpose of staining. The stained teeth were randomly divided into four groups $(n=15)$ corresponding to the mode of intervention for stain removal.

The teeth were mounted on a block and positioned inside a light box containing a single light source and photographed using a digital camera (Canon 130od: 11 aperture, $1 / 8$ th shutter speed and 400 ISO film speed) against a green background for pre-intervention images. The digital camera was fixed at a $20 \mathrm{~cm}$ distance from the specimen surface, onto a tripod that was placed on the ground. The method and angulation of lighting and photography were maintained the same for all specimens. Once the images were obtained, they were then transferred to a computer.

The four groups used in the current study were: Group A- Colgate ${ }^{\circledR}$ Visible White toothpaste (Colgate- Palmolive India Ltd., Mumbai, India) Group B- Himalaya ${ }^{\circledR}$ Sparkling White toothpaste (Himalaya Herbal Healthcare, Bengaluru, India) Group C- Biomed $^{\circledR} \quad$ Superwhite toothpaste
(Organic Pharmaceuticals, LLC, Novgorod region, Russia)

Group D- Glaze prophylactic polishing paste (control group).

\subsection{Brushing apparatus}

A custom made brushing apparatus was constructed using the handle of powered toothbrush fixed into a customized plastic box packed with dental plaster mould. (Figure 1) The teeth in Group A, Group B and Group C were brushed using Oral- $\mathrm{B}^{\circledR}$ CrossAction Power-Battery Powered Electric Toothbrush (Oral-B, P\&G, Ohio, USA). A solution was prepared by dissolving $15 \mathrm{~g}$ of the toothpaste in $45 \mathrm{~mL}$ of water, for each group. ${ }^{10}$ The toothbrush was mounted in the customized mould with a tooth specimen fixed beneath it. (Figure 1) The brushing was done for two minutes for each specimen. A separate toothbrush head was used for each group. In Group D, all the teeth were subjected to prophylaxis using a prophylactic rotary brush and paste (glaze polishing paste) with a low speed hand piece (NSK Corporation, Japan).

Digital photographs were repeated under the same conditions for all the specimens.

\subsection{Software analysis of iron stain removal}

The pre and post- intervention images (Figure. 2,3 ) were transferred to a computer and evaluated using image color summarizer software (Image Color Summarizer 0.76 (C) 2006-2020 Martin Krzywinski http://mkweb.bcgsc.ca/colorsummarizer/?analyze). This software gave the $\mathrm{R}$ (red), G (green) and B (blue) values for the images. The RGB values were converted into $L^{*}$ [for the lightness/ luminosity from black (o) to white (100)], $\mathrm{a}^{*}[$ from green $(-)$ to red $(+)] \mathrm{b}^{*}$ [from blue $(-)$ to yellow $(+)$ ] parameters using the CIELAB converter in colormine software (ColorMine library, open- source, MIT licensed .NET project. http://colormine.org/convert/ rgb-to-lab). The L (value), $\mathrm{C}$ (chroma), and $\mathrm{H}$ (hue) parameters were obtained using RGB to $\mathrm{LCH}$ converter in the colormine software. $\Delta \mathrm{E}$ (the 
difference in the Lab parameter between two different points in the colorspace) was calculated using the same colormine software.

\subsection{Statistical analysis}

Data obtained was tabulated and analysed statistically. The differences in the treatment groups in terms of changes in the $\mathrm{L}^{*}, \mathrm{a}^{*}, \mathrm{~b}^{*}, \mathrm{C}$, Hand $\Delta \mathrm{E}$ parameters were analyzed using oneway ANOVA. In cases for which the results of ANOVA became significant, inter group comparison was carried out using bon ferroni multiple comparison test. Statistical analysis was performed using SPSS ${ }^{\circledR}$ software (IBM Corp. Released 2017. IBM SPSS Statistics for Windows, Version 25.o. Armonk, NY: IBM Corp.).

\section{RESULTS}

A total of 60 primary anterior extracted teeth were included in the study. In group A (Colgate Visible White toothpaste) pre-intervention values for $\mathrm{L}^{*}, \mathrm{a}^{*}$ and $\mathrm{b}^{*}$ were $84.79 \pm 2.87,1.41 \pm 1.06$ and $18.74 \pm 2.84$ whereas post intervention (brushing the samples with the toothpaste) values for $\mathrm{L}^{*}, \mathrm{a}^{*}$ and $\mathrm{b}^{*}$ were $89.35 \pm 3.10,1.41 \pm 1.06$, and $17.98 \pm 9.98$, respectively. A significant difference between pre and post-interventions values was observed in the $L^{*}$ and $b^{*}$ parameters. $(\mathrm{p}<0.05)$.

In group B (Himalaya Sparkling White toothpaste) pre-intervention values for $\mathrm{L}^{*}$, $\mathrm{a}^{*}$ and $b^{*}$ changed from $75.48 \pm 2.45,2.68 \pm 1.83$ and $21.66 \pm 5.27$ to post-interventions values, 78.87 $\pm 3.11,3.03 \pm .95$, and $22.85 \pm 3.93$ respectively. No significant difference was observed in the pre and post-intervention values of any parameters for this group.

In group $\mathrm{C}$ (Biomed Superwhite toothpaste) pre-intervention values for $\mathrm{L}^{*}, \mathrm{a}^{*}$ and $\mathrm{b}^{*}$ changed from $76.14 \pm 4.22,2.89 \pm .74$ and $23.14 \pm 4.30$ to post-intervention values, $80.40 \pm 3.03,2.49 \pm 1.42$ and $22.98 \pm 3.17$, respectively. The difference between pre and post-interventions values for the $\mathrm{L}^{*}$ and $\mathrm{b}^{*}$ parameters was found statistically significant. $(\mathrm{p}<0.05)$
In group D (prophylactic polishing paste), pre intervention values for $\mathrm{L}^{*}, \mathrm{a}^{*}$ and $\mathrm{b}^{*}$ changed from $71.75 \pm 4.24,3.02 \pm .70$ and $22.08 \pm 2.26$ to post-intervention values, $83.25 \pm 4.23,1.19 \pm .90$ and $23.63 \pm 3.95$, respectively. A significant difference was observed between pre and post-intervention values for $L^{*}$ and $b^{*}$ parameters. $(\mathrm{p}<0.05)($ Table 1$)$

Hence, significant differences $(\mathrm{p}<0.05)$ in the $\mathrm{L}^{*}$ and $\mathrm{b}$ * color parameters can be seen for group A, $\mathrm{B}$ and $\mathrm{D}$; however, the difference in the pre and post-intervention values of $\mathrm{a}^{*}$ parameter did not show a significant difference for any group.

With regard to the LCH parameter Group A, hue $(\mathrm{H})$ value changed from $85.59 \pm 3.16$ to $89.06 \pm$ 4.16 and chroma (C) from $18.82 \pm 2.85$ to $17.95 \pm$ 3.87 , and value for $\mathrm{L}$ being the same with $\mathrm{L}^{*}$, hence it was not mentioned again. In group $B$, hue (H) value changed from $84.52 \pm 4.17$ to $81.94 \pm$ 3.19 and chroma (C) from $24.26 \pm 4.88$ to $22.89 \pm$ 3.76. In group $\mathrm{C}$, the hue $(\mathrm{H})$ of the samples changed from $83.06 \pm 2.00$ to $83.71 \pm 3.35$ and chroma (C) from23.61 \pm 4.21 to $23.15 \pm 3.19$. In group $\mathrm{D}$, the hue $(\mathrm{H})$ values changed from $82.18 \pm$ 1.85 to $87.00 \pm 1.89$ and chroma (C) from $22.30 \pm$ 2.27 to $23.67 \pm 3.97$. A statistical significant difference was observed in terms of the chroma in groups A, C and D. ( $\mathrm{p}<0.05)$ No significant difference was observed in the terms of changes in hue for all the four groups. (Table 1)

The mean $\Delta \mathrm{E}$ values for sample teeth in the four groups were $5.28 \pm 2.14,4.62 \pm 2.88,5.07 \pm 2.73$, and $12.48 \pm 5.23$, respectively. One-way ANOVA revealed significant differences in the range of changes in $\Delta \mathrm{E}$ values among different toothpaste groups. $(\mathrm{p}<\mathrm{0.05}$ ) (Table 2) Considering the significant results for $\Delta \mathrm{E}$ values, intergroup comparison in this regard was carried out. Intergroup comparison of $\Delta \mathrm{E}$ values revealed significant differences between group A, B, C and D respectively. $(\mathrm{p}<0.05)$ (Table 3$)$. 


\section{DISCUSSION}

Black extrinsic tooth stains have a prevalence of 1 to $20 \%$ in children. They are characterized by dark lines or incomplete amalgamation of dark dots on the cervical third of enamel. ${ }^{11}$ The pellicle layer is a proteinaceous organic film on tooth surface and also serves as a protective barrier. It also acts as a substrate for bacterial growth which ultimately leads to formation of dental plaque and has the tendency to absorb pigments causing extrinsic stains on teeth. ${ }^{12}$ Reid et al. (1977) suggested that the cause of pigmentation in children's teeth was probably ferric sulphide, formed by the reaction between hydrogen sulphide produced by bacteria and iron in the salivary or gingival exudate. Black stain influences the esthetics of teeth and is difficult to remove with a regular dentifrice and toothbrush. ${ }^{13}$ Therefore the present study evaluated the iron stain removal efficacy of Colgate $^{\circledR}$ Visible White, Himalaya ${ }^{\circledR}$ Sparkling White and Biomed ${ }^{\circledR}$ Superwhite dentifrices in comparison with dental prophylactic polishing paste.

The stain removal efficacy can be assessed by visual assessment with shade guides and indices. Digital assessment can be done using techniques such as colorimetry and spectrophotometry which measures the color changes after intervention in teeth. Computer analysis of digital images can also be done to assess the efficacy of stain removal. Digital images offer an objective shade difference value and are very sensitive for minor changes in stain removal. A standardized method must be employed in relation to camera, light and positioning of the teeth. ${ }^{14}$ Hence, in present study all digital equipment including camera, software, lighting and positioning of teeth were standardised increasing the accuracy of the study.

The current study measured $\mathrm{L}^{*}, \mathrm{a}^{*}, \mathrm{~b}$ * and $\mathrm{LCH}$ color parameters. In the terms of $\mathrm{LCH}$ parameters $\mathrm{L}^{*}$ is the degree of lightness and the values are same as $\mathrm{L}^{*}$ parameter in the Lab system. In accordance with the Munsell color chart, color has three parameters hue, value, and chroma. Hue $(\mathrm{H})$ is the perception of observer from the color and depends on different wavelengths of light beams that reach the eyes. Value (L) is the achromatic dimension of color and indicates its lightness or darkness. Higher the value, lighter the color and lower the value, darker the color. Chroma (C) is the intensity of color. A greater the value of chroma means more richness in the color. ${ }^{15}$

Nowadays, a vast selection of dentifrices are available in the market, specifically addressing removal of pellicle associated extrinsic stains. These dentifrices include higher quantities of abrasives and detergents; in order to remove tough stains. ${ }^{16}$ Different abrasivity of toothpastes depends on the hardness, shape, size and amount of the abrasive particles in the toothpaste. The active ingredients in a dentifrice include enzymes that dissolve pellicle proteins or chelating agents that have stain-dissolving properties. Alumina, dicalcium phosphate dihydrate, silica, calcium carbonate, and calcium pyrophosphate are some of the abrasives that are included in whitening toothpastes. ${ }^{17}$

In the current study, Colgate ${ }^{\circledR}$ Visible white was used. The abrasive agent present in Colgate ${ }^{\circledR}$ visible white consists of silica and polyphosphates. The cleaning efficacy of silica is similar to the abrasive materials used for cleaning and polishing as it physically removes surface stains. The polyphosphates are commonly used to prevent surface staining due to plaque formation. ${ }^{13}$ The changes in $\mathrm{L}^{*}$ and $\mathrm{b}^{*}$ parameter values for iron stain removal using Colgate $^{\circledR}$ visible white, in the current study were statistically significant which may be explained due to the different abrasive contents of the dentifrice. This is similar to the results obtained in the studies by Gerlach et al. ${ }^{18}$, Horn et al. ${ }^{19}$ and Ghassemi et al. ${ }^{20}$ who tested whitening dentifrices, and obtained satisfactory results regarding changes in tooth coloration. They concluded that these results may have been due to the presence of high performance abrasive agents contained such as silica, during the use of these toothpastes. 
Biomed $^{\circledR}$ Superwhite dentifrice used in the present study contains pineapple extract bromelain which helps clean enamel of dental plaque. The other ingredients include calcium phosphate polishes the enamel. Himalaya ${ }^{\circledR}$ Sparkling white toothpaste contains papain and bromelain which are proteolytic enzymes as tooth whitening agents. They disrupt and remove the protein portion of the pellicle layer thus removing the stains that are bound to these proteins. Papain is a natural enzyme, derived from latex of the Papaya fruit (Carica papaya). It is known to possess the ability to hydrolyze large proteins into smaller peptides and amino acids. ${ }^{21}$ Bromelain is extracted from the stem and fruit of Pineapple (Ananascomosus) plant. ${ }^{22}$ In the current study a significant difference was observed in the $L^{*}$ and $b^{*}$ parameters for Biomed ${ }^{\circledR}$ Superwhite toothpaste whereas no significant difference was observed in the pre and post brushing values in any parameters for Himalaya ${ }^{\circledR}$ Sparkling white toothpaste. In studies reported by Kalyana et al. ${ }^{10}$, and Patil et al. ${ }^{23}$, the ability of these proteolytic enzymes was demonstrated. They used a control dentifrice as Colgate ${ }^{\circledR}$ regular, since the relative dentine abrasive value was nearly the same as test dentifrice containing proteolytic enzymes. A significant increase in the mean $L^{*}$ values for the test dentifrice group could partly be attributed to these enzymes. Another clinical study using toothpaste containing a mixture of papain, alumina and sodium citrate (Rembrandt) has also reported a significant stain removing property. ${ }^{24}$

In the current study Colgate $^{\circledR}$ Visible White showed the greatest $\Delta \mathrm{E}$ after prophylactic paste and was found to be more efficient than the other toothpastes. Colgate ${ }^{\circledR}$ Visible White and Biomed ${ }^{\circledR}$ Superwhite toothpastes were more effective in improving tooth color and removing stains than Himalaya ${ }^{\circledR}$ Sparkling white toothpaste. The use of toothpastes with a toothbrush enables a benefitting action from both the abrasiveness of toothbrush and the physicochemical properties of toothpaste in stain removal. The decreased intensity of stains may also occur due to narrowing of the stain layer owing to this abrasive action. ${ }^{4}$

Dental prophylaxis is a commonly used technique to remove stains, dental plaque and calculus. However it requires an office visit. The abrasives in the prophylactic paste clean stains on the tooth surface which results in a whitening effect. ${ }^{24}$ In the current study all interventions caused color changes in teeth, but prophylactic polishing paste was the most effective as compared to all other groups.

Limitations of the study were smaller sample size and lack of consideration regarding interaction with saliva and various other food substances in the oral cavity. The study of specimens in the clinical setting would be more advantageous. More research is recommended in relation to the oral environment.

\section{CONCLUSION}

The maximum stain removal efficacy was demonstrated by prophylactic polishing paste as compared to other three commercial toothpastes available in market. Therefore it is recommended that a regular dental prophylaxis serves a dual purpose of iron stain removal in children taking iron supplements and for the maintenance of dental and gingival health.

\section{FUNDING}

Financial support and sponsorship: This research did not receive any specific grant from funding agencies in the public, commercial, or not-forprofit sectors.

\section{COMPETING INTERESTS}

Conflicts of interest: There are no conflicts of interest.

\section{REFERENCES}

1. Goldstein RE, Patzer G. Concepts of Dental Esthetics. Ronald E. Goldstein's Esthetics in Dentistry. 2018; 20:1-22. 
2. Gupta T, Sadana G, Rai HK. Effect of Esthetic Defects in Anterior Teeth on the Emotional and Social Well-being of Children: A Survey. Int J ClinPediatr Dent. 2019;12(3):229-232.

3. Abanto J, Carvalho TS, Mendes FM, Wanderley MT, Bönecker M, Raggio DP. Impact of oral diseases and disorders on oral health-related quality of life of preschool children. Community Dent Oral Epidemiol. 2011;39(2):105-114

4. Heidari A, Shahrabi M, Shahrabi MS. Efficacy of Three Toothpastes in Iron Stain Removal from Primary Teeth. Int $J$ ClinPediatr Dent. 2019;12(1):10-14.

5. Watts A, Addy M. Tooth discoloration and staining. A review of the literature. Br Dent J 2001 Mar;190(6):309-316.

6. Nordbo H, Eriksen HM, Rolla G, Attramadal A, Solheim H. Iron staining of the acquired enamel pellicle after exposure to tannic acid or chlorhexidine: preliminary report. Scand $J$ Dent Res. 1982;90(2):117-23.

7. Watts A, Addy M. Tooth discolouration and staining: a review of the literature. Br Dent J. 2001;190(6):309-16.

8. Christofides A, Asante KP, Schauer C, Sharieff W, Owusu-Agyei S, Zlotkin S, et al. Multi-micronutrient Sprinkles including a low dose of iron provided as microencapsulated ferrous fumarate improves haematologic indices in anaemic children: a randomized clinical trial. Matern Child Nutr. 2006;2(3): 169-80.

9. Soeteman GD, Valkenburg C, Van der Weijden GA, Van Loveren C, Bakker EWP, Slot DE. Whitening dentifrice and tooth surface discoloration-A systematic review and meta-analysis.Int J Dent Hygiene. 2018; 16(1):24-35.

10. Kalyana P, Shashidhar A, Meghashyam B, SreeVidya KR, Sweta S. Stain removal efficacy of a novel dentifrice containing papain and Bromelain extracts-an in vitro study. Int J Dent Hygiene. 2011;9(3):229-33.

11. Zhang F, Li Y, Xun Z, Zhang Q, Liu H, Chen F. A preliminary study on the relationship between iron and black extrinsic tooth stain in children. Lett ApplMicrobiol. 2017; 64(6): 424-429.

12. Tadikonda A, Pentapati KC, Urala AS, Acharya S. Anti-plaque and anti-gingivitis effect Papain, Bromelain, Miswak and Neem containing dentifrice: A randomized controlled trial. J ClinExp Dent. 2017;9(5): e649-53.

13. Reid JS, Beeley JA, MacDonald DG. Investigations into black extrinsic tooth stain. J Dent Res. 1977;56(8):895-899.

14. Kalsi A, Gupta S. Comparative Evaluation of the Bleaching Efficacy of Colgate Visible White, Close-Up Diamond Attraction Compared With Pola Office Plus. Biomed J Sci \& Tech Res. 2017;1(6):1808-12.

15. Nickerson D. History of the Munsell color system and its scientific application. JOSA. 1940;30(12):575-86.

16. Joiner A. Whitening toothpastes: a review of the literature. J Dent.2010;38:e17-e24.

17. Yaghini J, Mogharehabed A, Kaveh M, Mousazadeh H, Madani M. Effect A comparative Study of the Abrasive Effects of Different Toothpastes on Enamel. J Dent Sch 2012; 29(4):274-282.

18. Gerlach RW, Barker ML, Hyde JD, Jones MB, Cordero RE. Effects of a tartar control whitening dentifrice on tooth shade in a population with long-standing natural stain. J Clin Dent. 2001;12(2):47-50.

19. Horn BA, Bittencourt BF, Gomes OM, Farhat PA. Clinical evaluation of the whitening effect of over-the-counter dentifrices on vital teeth. Braz Dent J. 2014;25(3):203-206.

20. Ghassemi A, Vorwerk L, Cirigliano A, Hooper W, DeSciscio P, Nathoo S. Clinical Effectiveness Evaluation of a New Whitening Dentifrice. J Clin Dent. 2015;26(3):66-71.

21. Lowe G. The Structure and Mechanism of Action of Papain. Philos Trans R SocLond B Biol Sci. 1970;257:237-48.

22. Kelly GS. Bromelain: A Literature Review and Discussion of its Therapeutic Applica- tions. Alt Med Rev 1996;1:243-57.

23. Patil PA, Ankola AV, Hebbal MI, Patil AC. Comparison of effectiveness of abrasive and enzymatic action of whitening toothpastes in 
removal of extrinsic stains - a clinical trial. Int J Dent Hyg. 2015;13(1):25-29.

24. Emling RC, Shi X, Yankell SL. Rembrandt toothpaste: stain removal following the use of Peridex. J Clin Dent. 1992;3(2):66-69.
25. Li Y. Stain removal and whitening by baking soda dentifrice: A review of literature. $\mathrm{J}$ Am Dent Assoc. 2017;148(11S):S20-S26.

Table 1: Pre and post-intervention values for all four groups.

\begin{tabular}{|c|c|c|c|c|}
\hline \multirow[t]{2}{*}{ Group } & \multirow[t]{2}{*}{ Parameter } & \multicolumn{2}{|c|}{ Mean \pm Std. Dev. } & \multirow[t]{2}{*}{ p Value } \\
\hline & & Pre-intervention & Post- intervention & \\
\hline \multirow[t]{5}{*}{ A (Colgate Visible White) } & $\mathrm{L}^{*}$ & $84.79 \pm 2.87$ & $89.35 \pm 3.10$ & $.036 \pi$ \\
\hline & $a^{*}$ & $1.41 \pm 1.06$ & $.21 \pm 1.05$ & 0.104 \\
\hline & $b^{*}$ & $18.74 \pm 2.84$ & $17.98 \pm 9.98$ & 0.0039 \\
\hline & $\mathrm{H}$ & $85.59 \pm 3.16$ & $89.06 \pm 4.16$ & .061 \\
\hline & $\mathrm{C}$ & $18.82 \pm 2.85$ & $17.95 \pm 3.87$ & $.002 \pi$ \\
\hline \multirow[t]{5}{*}{$\begin{array}{l}\text { B (Himalaya Sparkling } \\
\text { White) }\end{array}$} & $\mathrm{L}^{*}$ & $75.48 \pm 2.45$ & $78.87 \pm 3.11$ & 0.37 \\
\hline & $a^{*}$ & $2.68 \pm 1.83$ & $3.03 \pm .95$ & 0.394 \\
\hline & $b^{*}$ & $21.66 \pm 5.27$ & $22.85 \pm 3.93$ & 0.181 \\
\hline & $\mathrm{H}$ & $84.52 \pm 4.17$ & $81.94 \pm 3.19$ & .083 \\
\hline & $\mathrm{C}$ & $24.26 \pm 4.88$ & $22.89 \pm 3.76$ & .199 \\
\hline \multirow[t]{5}{*}{ C (Biomed Superwhite) } & $L^{*}$ & $76.14 \pm 4.22$ & $80.40 \pm 3.03$ & 0.027 व \\
\hline & $a^{*}$ & $2.89 \pm .74$ & $2.49 \pm 1.42$ & 0.932 \\
\hline & $b^{*}$ & $23.14 \pm 4.30$ & $22.98 \pm 3.17$ & 0.004 व \\
\hline & $\mathrm{H}$ & $83.06 \pm 2.00$ & $83.71 \pm 3.35$ & .742 \\
\hline & $\mathrm{C}$ & $23.61 \pm 4.21$ & $23.15 \pm 3.19$ & $.005 \pi$ \\
\hline \multirow[t]{5}{*}{$\begin{array}{c}\mathrm{D} \text { (Prophylactic polishing } \\
\text { paste) } \\
\end{array}$} & $\mathrm{L}^{*}$ & $71.75 \pm 4.24$ & $83.25 \pm 4.23$ & $0.026 \pi$ \\
\hline & $\mathrm{a}^{*}$ & $3.02 \pm .70$ & $1.19 \pm .90$ & 0.664 \\
\hline & $b^{*}$ & $22.08 \pm 2.26$ & $23.63 \pm 3.95$ & $.002 \pi$ \\
\hline & $\mathrm{H}$ & $82.18 \pm 1.85$ & $87.00 \pm 1.89$ & .063 \\
\hline & $\mathrm{C}$ & $22.30 \pm 2.27$ & $23.67 \pm 3.97$ & $.002 \pi$ \\
\hline
\end{tabular}


Table 2: Mean $\Delta E$ (color difference) values for all four groups.

\begin{tabular}{|c|c|c|c|c|c|}
\hline & & & \multicolumn{2}{|c|}{$\begin{array}{r}\text { Mean Confidence Interval for } \\
\text { Mean }\end{array}$} \\
\hline Group & Mean $\Delta E$ & Std. Dev. & Lower Bound & Upper Bound & p Value \\
\hline $\begin{array}{c}\text { A (Colgate Visible } \\
\text { White) }\end{array}$ & 5.28 & 2.14 & 3.75 & 6.82 & \\
\hline $\begin{array}{c}\text { B (Himalaya } \\
\text { Sparkling White) }\end{array}$ & 4.62 & 2.88 & 2.56 & 6.69 & \\
\hline $\begin{array}{c}\text { C (Biomed } \\
\text { Superwhite) }\end{array}$ & 5.07 & 2.73 & 3.12 & 7.02 & 0.001 I \\
\hline $\begin{array}{c}\text { D (Prophylactic } \\
\text { polishing paste) }\end{array}$ & 12.48 & 5.23 & 8.74 & 16.22 & \\
\hline Total & 6.86 & 4.67 & 5.37 & 8.36 & \\
\hline \multicolumn{7}{|c|}{ ๆ denotes significant p value (p<0.05) } \\
\hline
\end{tabular}

Table 3: Inter-group analysis using bon-ferroni test for $\Delta E$.

\begin{tabular}{|c|c|c|c|c|}
\hline Groups & Colgate & Himalaya & Biomed & Prophy paste \\
\hline $\begin{array}{c}\text { A (Colgate Visible } \\
\text { White) }\end{array}$ & - & 1.00 & 1.00 & $0.000 \rrbracket$ \\
\hline $\begin{array}{c}\text { B (Himalaya } \\
\text { Sparkling White) }\end{array}$ & 1.00 & - & 1.00 & $0.000 \rrbracket$ \\
\hline $\begin{array}{c}\mathrm{C} \text { (Biomed } \\
\text { Superwhite) }\end{array}$ & 1.00 & 1.00 & - & $0.000 \rrbracket$ \\
\hline $\begin{array}{l}\text { D (Prophylactic } \\
\text { polishing paste) }\end{array}$ & $0.000 \pi$ & $0.000 \rrbracket$ & 0.000 ฯ & - \\
\hline
\end{tabular}

Figure Legends:

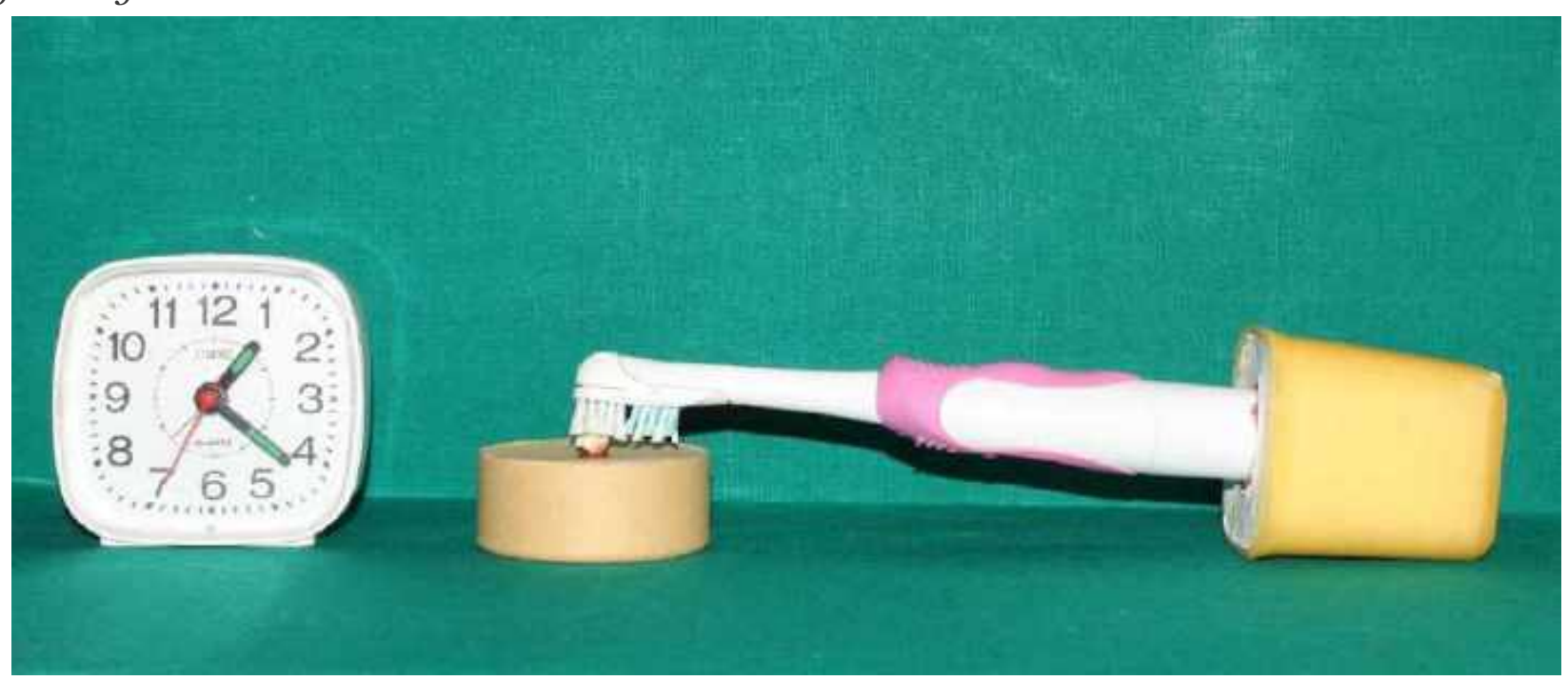

Fig. 1: Brushing apparatus used for stain removal 


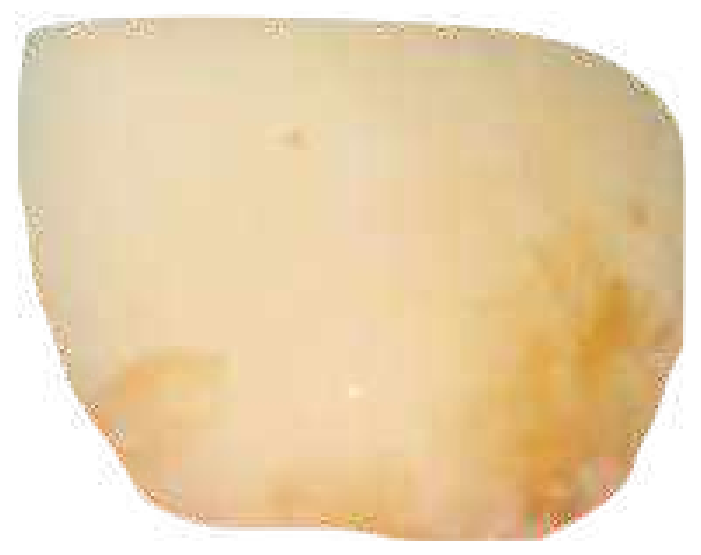

Fig.2: Pre-intervention digital image used for analysis of tooth in Group D

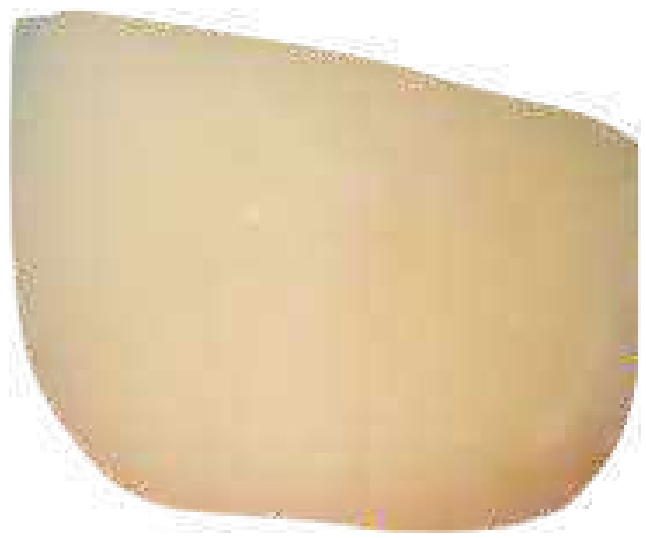

Fig.3: Post-intervention digital image used for analysis of tooth in Group D 